\title{
Exploration and Analysis of Health Education in College Physical Education
}

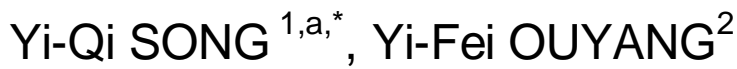 \\ ${ }^{1}$ Department of Physical Education, North China Institute of Science and Technology, Hebei \\ 065201, China \\ ${ }^{2}$ National Institute for Nutrition and Food Safety, Chinese Center for Disease Control and Prevention, \\ Beijing, 100050, China \\ asongyq1981@yeah.net \\ ${ }^{*}$ Corresponding author
}

Keywords: college; physical education; health education

\begin{abstract}
Physical education and health education have something in common in the purpose, both of which are to promote the physical and mental development of students. They also have something overlapped in the content, for both are to teach students knowledge and skills of sports and health. College sports have flexible and diverse forms and can act as a good carrier for health education of college students. To better combine them, colleges and universities need to strengthen the training of sports teachers and improve curriculum design and curriculum evaluation.
\end{abstract}

\section{Introduction}

In recent years, Chinese schools have significantly improved their sports teaching conditions, but young people still have a serious problem of insufficient exercises and worrying physical health. On July 29, 2014, Chinese vice premier Liu Yandong emphasized at the forum of national physical education that health was the foundation of an adolescent's growth, success and happiness and had something to do with the future of the country and the nation as well as well-being of millions of families. School sports activities should be strengthened so that students can have a healthy body, a healthy personality, a lifelong exercising habit and a healthy lifestyle. Therefore, the reform of school sports system and mechanism should be deepened to establish a scientific evaluation system, strengthen the teaching staff and increase funding so as to improve school sports facilities [1].

College physical education assumes an important responsibility for personnel training and health promotion, and its new tasks in the new historical period are to improve the curriculum idea and content and optimize the curriculum structure. The combination of physical education and health education can further promote student to learn health knowledge and form good behavior habits and has great significance for the physical and mental development of students.

\section{Health conditions of students}

Health test data of Chinese students in 2010 showed that students had improved their fitness and health as well as nutritional status, but there were still some problems [2].

\section{College students continue to have a slow decline in physical fitness}

Data showed that the group of students at the age of 19-22 had a further decline in explosive power, strength, endurance and other physical fitness levels except sit and reach, but compared with previous five-year data, the decline degree was slightly reduced. Compared with 2005, the performance of urban and rural boys at the age of $19-22$ in standing long jump was reduced by $1.29 \mathrm{~cm}$ and $0.23 \mathrm{~cm}$ on the average, that in chin-up by 1.44 times and 1.45 times and that in $1,000 \mathrm{~m}$ run by $3.37 \mathrm{~s}$ and $3.09 \mathrm{~s}$; the 
performance of urban and rural girls in standing long jump was reduced by $2.72 \mathrm{~cm}$ and $0.92 \mathrm{~cm}$ on the average, that in sit-ups by 3.02 times/min and 2.48 times/min and that in $800 \mathrm{~m}$ run by $3.17 \mathrm{~s}$ and $1.87 \mathrm{~s}$.

\section{The detectable rate of poor sight continues to rise}

Data showed that the rate of poor sight in Chinese student was still high, which was $40.89 \%$ in the pupils at the age of 7-12 with an increase of 9.22 percentage points compared with $2005,67.33 \%$ in the junior high school students at the age of 13-15 with an increase of 9.26 percentage points, $79.20 \%$ in the senior high school students at the age of 16-18 with an increase of 3.18 percentage points and $84.72 \%$ in the college students at the age of 19-22 with an increase of 2.04 percentage points.

\section{The detectable rate of obesity continues to increase}

Data showed that the detectable rate of obesity and overweight in Chinese students continued to increase. The detectable rate of obesity in urban boys, urban girls, rural boys and rural girls at the age of $7-22$ was $13.33 \%, 5.64 \%, 7.83 \%$ and $3.78 \%$, with an increase of $1.94,0.63,2.76$ and 1.15 percentage points compared with 2005, and that of overweight was $14.81 \%, 9.92 \%, 10.79 \%$ and $8.03 \%$ with an increase of 1.56, 1.20, 2.59 and 3.42 percentage points compared with 2005 .

\section{Meaning and content of health education}

Health education is to carry out planned, organized and systematic educational activities, so that people can consciously adopt healthy behaviors and lifestyles to eliminate or mitigate the effects of health risk factors so as to prevent diseases and improve health and living quality. Its core is to educate people to establish health awareness and encourage people to change unhealthy behaviors and lifestyle so that they can develop good behaviors and lifestyles to reduce or eliminate the impact of health risk factors. Its main contents include: physical health knowledge education, behavior and lifestyle education, sex and sexual health education, environment and health relationship education, self-care method education, mental health education, health knowledge education and AIDS, VD and drug hazards and prevention education [3].

\section{Advantages and disadvantages of health education in physical education}

\section{Advantages}

They have something in common in the purpose. The main purpose of college physical education is to use various sports activities in and out of class to teach sports and health knowledge, enhance students' physical fitness and promote their physical and mental development; while the main purpose of health education is to teaching health knowledge, train students' health awareness, promote the formation of their healthy behaviors. The purposes of both have something overlapped, but in essence, they both aim at the comprehensive development of college students' physical and mental health.

They have overlapped contents. The main content of physical education is various forms of physical exercise, such as track and field, basketball, football, volleyball, sports dance, aerobics and martial arts that students can participate in to improve their physical fitness and function, and at the same time in order to enable students to better understand knowledge of the movements and exercises, colleges and universities usually arrange some theoretical teaching; the content of health education usually involve a balanced diet, regular exercise, mental balance, drug safety, disease prevention and control, etc. It can be seen that their contents have something overlapped, especially in diet, exercise and mental balance. Relevant contents can be taught through sports practice and theoretical teaching to help students learn basic knowledge and skills of sports and health.

Colleges and universities have various forms of sports which can serve as a good carrier for health education. College sports should be conducted in the form of practical exercises, theoretical teaching, classroom teaching, extra-curricular activities, various cultural lectures, quiz show, etc. In these forms of 
activity, theoretical concepts related to health education can be included to deepen college students' understanding of healthy living and promote college students to form healthy living habits.

\section{Disadvantages}

Physical education and health education are overlapped and complementary in purpose, content and form, but to effectively complete health education in college physical education, there is a lot of work to complete. People are the subject of actions, so the excellent faculty is indispensable for the successful completion of a variety of teaching activities. In addition, the theory of health education involves many things including sports, fitness, nutrition, psychology, public health, etc., so the requirement for the teacher's ability is also higher, and the physical education teacher subject to restrictions of the discipline system may have insufficient knowledge, thereby affecting the effectiveness of teaching. Therefore, physical education teachers need to strengthen their learning, the college should also provide appropriate training services, and more importantly, in terms of sports personnel training, corresponding agencies should make adjustments to meet the needs of social development in the new period.

To achieve the teaching purpose of health education, not only good teachers are required, but also the curriculum design, including textbook compilation, content selection, teaching arrangement and teaching evaluation, needs to be improved. The combination of college physical education and health education is a systematic engineering, which cannot be established and completed before careful design, scientific verification and practice test. Although some domestic universities have a try and obtain some experience, there are still some problems that are not reasonably settled and lack of overall planning at the national level. Therefore, relevant authorities should pay enough attention, fully understand the importance of the combination of physical education and health education, conduct related researches and work out detailed and comprehensive planning recommendations as soon as possible.

\section{Conclusion and recommendations}

College physical education and health education have something consistent in the purpose, both of which are to improve students' health and promote their physical and mental development. They also have something overlapped in the content, both of which are to teach students scientific sports knowledge, nutritional and dietary knowledge and mental health knowledge. At the same time, college physical education is a good carrier for health education to college students, and multiple channels in and out of class can be used to transmit knowledge to students. Therefore, it is feasible to combine college physical education and health education so that not only knowledge can be taught but also college students' physical and mental development can be promoted.

However, in order to get better teaching effect and make students effectively master relevant theoretical knowledge and skills and form healthy living behaviors and habits, attention needs to be paid to the followings: first, universities should strengthen the training of physical education teachers' teaching ability so that they can master necessary knowledge, theory and skills of health education; second, universities should improve the curriculum design of physical and health education, including the syllabus, textbook planning, teaching content and curriculum evaluation and develop relevant education policy from the national level .

\section{References}

[1] Liu Yandong. China Education Daily[EB/OL]. ( July 30, 2014)[Sept 1, 2014]. http://www.jyb.cn/china/gnxw/201407/t20140730_592239.html

[2] Ministry of Education of the People's Republic of China. Results Announcement of the Ministry of Education on 2010 National Student Physical Fitness and Health Survey. [EB/OL]. ( Aug 29,

2014)[Sept 1, 2014].

http://www.moe.gov.cn/publicfiles/business/htmlfiles/moe/s5948/201109/124202.html 
[3] Xu Xiaoyang. Reflections on Content of Health Education. Journal of Physical Education, 2002, (4): 59-61.

[4] Du Juying. Reflections on Physical and Health Education to College Students. J of Wuhan Institute of Physical education. 2005, 39(2): 12-15. 